\title{
Sobre a tradução de o curso filosófico, de Jean François Lyotard
}

\section{André Luis La Salvia}

Professor da Universidade Federal do ABC, São Bernardo do Campo, São Paulo, Brasil. la.salvia@ufabc.edu.br

ORCID: https://orcid.org/0000-0002-1111-5052

Recebido em 29 de outubro de 2018

Aprovado em 11 de dezembro de 2018

Publiado em 30 de janeiro de 2019

Aqueles que pesquisam o ensino de filosofia podem se deparar frequentemente com uma referência a importância da leitura, mais especificamente com uma diferenciação entre ler textos filosóficos e a leitura filosófica de textos de qualquer natureza. Não se encontra essa distinçãoapenas nas orientações curriculares (2009), mas também em muitos outros pensadores que, para ficar em apenas alguns exemplos, podemos citar Favaretto (1993), Fabbrini (2005), Murcho (2008) e Johanson (2013).

E em todos esses autores a referência é um texto chamado Le cours philosophique de Jean François Lyotard, publicado no livro Le Greve de philosophes que é uma coletânea de comunicações e debates do evento "Encontro Escola e Filosofia" que ocorreu em 20 e 21 de outubro de 1984 na Universidade de Paris X - Nanterre. Este artigo de Lyotard, apesar de fonte de pesquisa para muitos textos brasileiros, possui apenas uma tradução publicada em Portugal, dentro de uma coletânea chamada O pós-moderno explicado às crianças: correspondência 1982-1985.

Este colóquio ocorreu em função das modificações que a Lei $n^{\circ} 84-52$, de 26 de janeiro de 1984 fez no ensino superior francês ${ }^{1}$. Por ser uma transcrição das conferências nesse encontro, a obra possui muitas outras contribuições como as de Joseph Leif, de François Chatelet, de Jean Hebrard, de Francine Best, de Jacques Ranciere, entre outros. Les greve des philosophes é muitas vezes mais estudado por sua Carta Prefácio escrita por Jacques Derrida. De modo geral, o tom do colóquio é de valorização da filosofia, pois seu tema era "Não há escola sem filosofia", marcando um tom crítico ao que consideravam um declínio do papel da filosofia na formação de professores, pelo menos é o que atestam algumas pesquisas sobre Derrida, como por exemplo Ceppas (2002), Cahen (2001) e Orchard (2011). 
Acreditamos que a filosofia é necessária na escola, do ensino fundamental ao médio. Dado as suas características de problematização, investigação, argumentação e sistematização, o texto filosófico é uma fonte de conteúdos bem como de métodos que podem em muito auxiliar na expansão da compreensão da realidade e no desenvolvimento das competências leitoras e escritoras. Principalmente no ensino médio, o texto filosófico, ou a leitura filosófica de textos outros, pode desempenhar um papel importante na didática da aula. Nesse sentido, a tradução desse texto de Lyotard é muito importante nos cursos de formação de professores de filosofia, uma vez que foi ele que introduziu e diferenciou esses dois tipos de leitura.

Para essa tradução mantivemos em colchetes a paginação do original.

\section{O curso filosófico, de Jean-François Lyotard}

In: La Greve des philosophiques, école et philosophie, editions Osirirs, Paris, mars 1986, pp. 34-40

[34] Se eu acreditar no prospecto desse Encontro, a questão fixada aqui para nossa reflexão é aquela da formação filosófica dos professores, admite-se que "educar e instruir são atos filosóficos".

Eu não sei o que significa "ato filosófico". Eu darei a palavra ato um sentido estrito, que se opõe a potência. E direi que a filosofia não é uma entidade, uma potência, um corpo de saber, de saber-fazer, de saber-sentir, mas que ela é somente em ato. Eu acrescento que educar e instruir não me parecem nem mais nem menos atos filosóficos do que banquetear ou armar um navio. A filosofia não é um terreno cortado na geografia das disciplinas. Nós sabemos isso tudo.

Eu digo 'curso filosófico' como dizemos 'andar do tempo'. Nós sabemos que ao redor da palavra formação, bildung, e portanto ao redor da pedagogia e da reforma, joga-se na reflexão filosófica desde Protágoras e Platão, desde Pitágoras, uma partida principal. Ela pressupôs que o espirito dos homens não foi dado a eles como precisam e que deve ser re-formado. O monstro dos filósofos é a infância. É também seu cúmplice. A infância lhes diz que o espírito não é dado. Mas que é possível.

Formar quer dizer que um mestre vem ajudar o espirito possível, à espera na infância para se realizar. Vocês conhecem o círculo vicioso: mas e o próprio mestre? Como ele se emancipa de sua monstruosidade infantil? Educar os educadores, reformar os reformadores: seguimos a aporia de Platão, por Kant, até Marx. É preciso dizer como na psicanálise: assim como havia autoanálise fundadora, haveria uma autoformação fundadora? Um autodidata pai de todas as didáticas? 
[35] Uma diferença dos filósofos com os psicanalistas é que eles tem muitos pais, demais para admitir uma paternidade. No entanto, filosofar é, em primeiro lugar, uma autodidática.

É isto que eu quero dizer em primeiro lugar por curso filosófico. Não podemos ser um mestre, dominar o curso. Não podemos expor uma questão sem nos expor. Interrogar um assunto (a formação, por exemplo) sem ser interrogado por ele. Ou seja, sem se reconectar com essa época da infância, aquela das possibilidades do espirito.

É preciso recomeçar. Não pode ser filósofo o espirito, incluindo o espirito do professor de filosofia, quem chega cheio sobre a questão e, em classe, não recomeça. Não retoma o curso pelo começo. Primeiramente sabemos que esse trabalho deve ter lugar não importa a ocasião de qual questão ou não importa qual assunto e, segundo, começar não significa tomar genealogicamente (como se a genealogia, e em particular, a serialidade/diacronia historiadora, não interrogasse). O monstro infantil não é o pai do homem, ele está no meio do homem, seu de-curso, seu desvio possível, ameaçador. Nós começamos sempre no meio. É por isso que o projeto de um currículo filosófico, projeto emprestado das ciências exatas, parece condenado ao fracasso.

Da mesma forma, autodidata não significa que não aprendemos nada dos outros. Mas somente que não aprendemos nada se eles não fazem aprender a desaprender. O curso filosófico não se propaga como um saber se transmite. Por aquisição.

Isso é claro no caso da leitura filosófica, que fornece o principal do diálogo que temos conosco mesmo sobre um assunto. Esta leitura não é filosófica porque os textos lidos são filosóficos - eles podem ser dos artistas, dos cientistas, de política também, é nós podemos ler textos filosóficos sem filosofar - ela só é filosófica se ela é autodidática. Se ela é um exercício desconcertante em relação ao texto, um exercício de paciência. O longo curso da leitura filosófica não ensina somente o que é preciso ler, mas que nós não paramos de ler, que só começamos, que não lemos o que lemos. Ela é um exercício de escuta.

Formar-se para a escuta na leitura, é se formar para retornar [36] perder sua boa forma. Reexaminar os pressupostos, os subentendidos, no texto e na leitura do texto. O essencial disso que chamamos elaboração, que acompanha e implanta a escuta paciente, consiste nessa anamnese, na pesquisa daquilo que fica ainda impensado enquanto já está pensado. É por isso que a elaboração filosófica não tem nenhuma relação com a teoria, nem a experiência desta elaboração com a aquisição de um saber (matema). E que a resistência que encontramos no trabalho de escuta e de anamnese é de outra natureza que aquela que pode se opor a transmissão de conhecimentos.

$\mathrm{O}$ curso trabalha a dita realidade. Ele decodifica os seus critérios. Ele a suspende. Se um dos principais critérios da realidade e do realismo é de poupar tempo, o que é, parece-me 
o caso hoje, então o curso filosófico não esta conforme a realidade de hoje. Nossas dificuldades como professores de filosofia tomam essencialmente as exigências da paciência. Que devemos suportar não progredir (de uma maneira calculável, aparente), de sempre começa isto é, contrário aos valores ambientais de prospectiva, de desenvolvimento, de segmentação, de performance, de rapidez, de contrato, de execução, de prazer. Quando eu ensinei nos estabelecimentos secundários, eu me lembro dessa constante: nós estávamos afogados, os alunos e eu, durante todo o primeiro trimestre. O curso começava, ou melhor, o começo começava, com os sobreviventes em janeiro. Foi necessário, é necessário, suportar a infância do pensamento eu sei que as condições como dissemos, não são mais as mesmas. Eu chego ao ponto.

Eu não ensino nada a vocês (por hipótese). Nós sabemos que o curso de filosofia tem o mesmo valor que o curso filosófico. O valor de transmitir sobre temas impostos ou não do programa, não somente esses exemplos desses trabalho de recomeço tirado da bibliografia filosófica, ou os signos desse mesmo trabalho emprestado da história da ciências, das técnicas, das artes, das políticas - então, não somente fazer conhecer esses exemplos e esses signos, os apresentar como o que é, como os referentes do discurso escolar - mas de inscrever um trabalho de escuta, anamnese, de elaboração na mesma classe, pragmaticamente. De inscrever atualmente no pequeno mundo dos nomes próprios onde durante duas horas está em jogo do curso naquele dia. E o que está em jogo é sempre, precisamente, que esse trabalho do pensamento tenha lugar, tenha curso, em classe, aqui e agora.

[37] Essa exigência não é "pedagógica". Ela não determina nenhum método de ensino. Não há ciência. Ao contrário: de que o curso filosófico tem lugar no curso de filosofia, ele resulta que cada sala, cada conjunto de nomes, datas, lugares, elabore seu idioma, idioleto no qual esse trabalho se faz. Há uma afinidade do autodidata com o idioleto.

Essa singularidade do curso de filosofia, eu quero dizer, nesse curso, e que marca o curso, é o mesmo que marca o curso filosófico. Eu quero dizer: escrever um texto filosófico sozinho na sua mesa (ou andando), resulta exatamente no mesmo paradoxo. Escrevemos antes de saber o que há para dizer e como, e para o saber, se é possível. Aescrita filosófica está adiantada sobre o que ela deveria ser. Como uma criança, ela é prematura, inconsistente. Nós recomeçamos, ela não é confiável, para esperar o pensamento lá no final. Mas o pensamento está aqui embaraçado com o não-pensamento, tentando desembaraçar a má língua da infância.

A primeira vista, então, não percebemos a diferença de natureza entre filosofar e ensinar filosofia. Kant diz: não aprendemos filosofia, aprendemos, no melhor dos casos, a filosofar (phil sophieren) [Arquitetônica da razão pura]. Estando sozinho ou com muitos, somos autodidatas, no sentido que é preciso filosofar para aprender a filosofar. 
Eu chego ao segundo ponto. Kant fez portanto, a diferença entre o conceito escolar (schu begriff) da filosofia e seu conceito mundano (weltbegriff). Nas escola, filosofar é esse exercício da paciência que se chama dialética em Kant, como em Aristóteles. Mas jogado no mundo, a filosofia deve assumir, diz Kant, uma responsabilidade segunda. Não somente ela prova o que é o pensar, mas ela é comparada a um ideal, ao ideal de um tipo de filósofo - que é, escreve Kant, "o legislador da razão humana". A filosofia posta no mundo é encarregada por relatar os conhecimentos, todos os conhecimentos as finalidades essenciais da razão humana. Eis a demanda que vem do mundo: ao trabalho especulativo (o trabalho de suportar de que falei) vem se juntar um interesse prático e popular da razão na filosofia do mundo. E como vocês sabem, e como Kant explica na dialética da primeira crítica, esses interessem são contraditórios.

[38] O professor de filosofia hoje, pertence a escola ou ao mundo? A modernidade, as luzes, a reflexão kantiana ela mesma, colocaram a escola no centro do interesse popular e prático da razão. Faz dois séculos, na França principalmente e de outro modo na Alemanha, o que está em jogo é a chamada formação do cidadão da república. A tarefa da filosofia se encontra confundida com aquela da emancipação. A emancipação para Kant é claramente a liberdade dada a razão de implantar e realizar os fins, a salvo de todos os pathos. Tal seria o legislador da razão humana.

Há nessa perspectiva 'moderna' o pressuposto seguinte: o mundo pede para a filosofia legislar prática e politicamente. Eu não lhes ensino nada dizendo: nós não nos perguntamos hoje, se o mundo está errado ou certo de endereçar esse pedido ao professor de filosofia (ele quem está no mundo para a escola moderna há dois séculos), nós nos perguntamos se o mundo endereça ainda alguma demanda desse tipo. Nenhum pedido direto.

Se é verdade que o curso de filosofia segue um curso filosófico, se é verdade que filosofar, sozinho ou em classe, obedece a uma demanda de retornar a infância do pensamento, o que acontece se o pensamento não tem mais infância? Se aqueles que são crianças e adolescentes deixam de ser o intermediário incerto do homem, a possibilidade das ideias? Se os interesses são fixados? Os professores do secundário na França, que eu conheço, para a filosofia, pelo menos, não precisam ser formados para filosofar. Eles são quer dizer, eles não serão nunca e está bem assim. Mas eles não podem atualizar o curso filosófico aos quais são capazes, porque os alunos não estão dispostos a ter paciência, a anamnese, ao recomeço.

Eu não vejo remédio pedagógico que não seja pior que a própria doença. Instruir professores que eles tem que ser amigáveis, preconizar a sedução, prescrever, captar a benevolência das crianças para os avanços demagógicos e dos aparelhos é um remédio pior que a doença. Nós tínhamos nas nossas aulas os Alcebiades que vinham nos tentar esse lado, a quem precisava mais cedo ou mais tarde fazer compreender, como fez Sócrates, que eles estavam prontos para uma troca de enganos, querendo trocar sua sedução 
por nossa sabedoria que é nula. O cúmulo seria que se recomendasse aos professores de filosofia que se façam [39] de Alcebiades de seus alunos. O trabalho de anamnese e de elaboração em ato numa sala, seja alegre ou severo, não deve nada ao aliciamento.

A dificuldade apresentada não é sem relação com aquela que encontra o Estrangeiro de Elea no Sofista (217c sq. 246c). Ele quer argumentar melhor por questões e respostas se o parceiro não tiver dificuldade de responder e se tem as rédeas soltas (enenios, de enia, o freio). Se esse não é o caso, é melhor argumentar sozinho. Pode-se dialogar com os amigos das formas, eles são melhor domesticados (hemeroteroi) que os materialistas que reduzem tudo ao corpo. Quanto a estes últimos, faz-se o trabalho de anamnese in absentia, inteiro só e em seu lugar. Fechamos a escola.

O declínio dos ideais modernos junto a persistência da instituição escolar republicana, que se apoiava neles, tem esse efeito de lançar no curso filosófico espíritos que não entram nele. Sua resistência parece invencível, precisamente porque ela é sem pegada. Eles falam o idioma que lhes ensinou e lhes ensina o mundo e o mundo fala de rapidez, gozo, narcisismo, competitividade, sucesso, conquistas. O mundo fala sobre as regras de trocas econômicas, generalizada a todos os aspectos da vida, compreendendo as afeições e os prazeres. Esse idioma é outro que aquele do curso filosófico, ele lhe é incomensurável. Não há juiz para resolver essa diferença. O aluno e o professor são vítimas um do outro. O dialético ou o dialógico não pode ter curso entre eles, somente o agnóstico.

Três observações para terminar:

Para começar, eu não tiro do que precede a conclusão que é preciso formar os professores de filosofia para a guerra (de palavras, naturalmente). Mas eu me recordo portanto que o motivo maior invocado por Aristoteles para estudar a retórica e a dialética é que aquele que tem razão na escola pode ser vencido na ágora. Ou a agora está, se eu não me engano, na escola atualmente. E que Kant se representa o filósofo (não o professor, eu concordo) como um guerreiro sempre em alerta, que usa a espada contra os mercadores da aparência transcendental. Nós devemos ser capazes de enfrentar a opinião da massa, maldosa. Mas é preciso elaborar nossa resolução tentar descobrir que sentido faz a luta.

[40] Em seguida, há uma solução platônica: selecionar os espíritos com os quais o curso filosófico pode ser prosseguido. Solução pitagórica: separamos os mathematikoi dos politikoi. É hoje romper com o democratismo em favor de uma república dos espíritos. E deixar a cargo dos outros gerir a demos. A filosofia torna-se opcional, ou ela é relegada ao superior, ou ensinada somente em certos estabelecimentos secundários. Tudo leva a uma saída desse género, o que nós temos. Ainda assim nós devemos elaborar uma conduta de pensamento, medir o que está em jogo. 
Enfim, é preciso não negligenciar isso: a demanda de anamnese, desconcertante, de elaboração não desapareceu, ela pode estar rarefeita, está sobretudo adiada. Em Vincennes, nós assistimos chegar no auditório um público de homens e mulheres que na vida ativa exercem as profissões mais diversas. Ainda assim, é a ágora, mas benevolente. Essa demanda por filosofia tem por motivo não tanto a asfixia da profissão que a obscuridade dos fins profissionais. Trata-se de profissões qualificadas, altamente qualificadas, científicas, jurídicas, médicas, artísticas, jornalísticas. A elevação geral da qualificação nas tarefas traz com ela um tipo de vanguardismo, as questões sobre a essência da atividade cumprida, um desejo de redesenhar a instituição. A filosofia ou o filosofar, deve desenvolver seu curso diante desses questionamentos esporádicos. É por exemplo que tenta fazer o Colégio Internacional de Filosofia. O pensamento tem talvez mais de infância disponível ao trinta e cinco anos que aos dezoito, e mais fora dos currículos que dentro.

\section{Referências}

BRASIL, MEC. Orientações curriculares para o ensino médio ; volume 3 - Ciências humanas e suas tecnologias / Secretaria de Educação Básica. - Brasília : Ministério da Educação, Secretaria de Educação Básica, 2006. 133 p.

CAHEN, Didier. Derrida and the question of education: a nex space for philosophy. In: Biesta, GJJ e Egea-Kuehne, D. Derrida \& Education. Routledge, London and New York, 2001. CEPPAS, Filipe. Antinomias no ensino de filosofia. In: Walter Kohan. (Org.). Ensino de Filosofia, perspectivas. 1ed.Belo Horizonte: Autêntica, 2002, v. 1, p. 87-96.

FABRINI, Ricardo. Ensino de filosofia: a leitura e o acontecimento. Trans/Form/Ação, São Paulo, 28(1): 7-27, 2005.

FAVARETTO, C. F. Sobre o ensino de filosofia. Revista da Faculdade de Educação, São Paulo, v. 19, n. 1, p. 97-102, jan.jun./1993.

JOHANSON, Izilda. Filosofia, filosófo e professor de filosofia. Revista da FAEEBA Educação e Contemporaneidade, Salvador, v. 22, n. 39, p. 55-62, jan./jun. 2013.

LYOTARD, J. F. O pós-moderno explicado às crianças: correspondência 1982-1985. 2. ed. Lisboa: Publicações Dom Quixote, 1993. 
MURCHO, Desidério. A natureza da filosofia e o seu ensino. Educ. e Filos., Uberlândia, v. 22, n. 44, p. 79-99, jul./dez. 2008.

ORCHARD, Vivienne. Jacques Derrida and the Instituition of French Philosophy. Legenda, Modern Humanities Research Association, New York, 2011.

\section{Notas}

${ }^{1}$ A lei também é conhecida como lei Savary (em homenagem ao ministro Alain Savary), realiza uma ampla reforma do ensino superior e, especialmente, das universidades. Para conhecê-la acesse: https://www.legifrance.gouv.fr/ affichTexte.do?cidTexte=JORFTEXT000000692733\&dateTexte=20000621, acesso 21/09/2018

\section{Correspondência}

André Luis La Salvia - Rua Arcturus, s/n Anchieta, Universidade Federal do ABC, Centro de Ciências Naturais e Humanas, CEP: 09.606-070, São Bernardo do Campo, São Paulo, Brasil

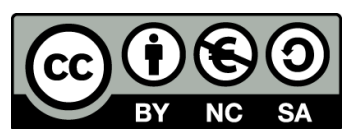

This work is licensed under a Creative Commons Attribution-NonCommercial 4.0 International (CC BY-NC 4.0) 